\title{
Discovery and Preclinical Evaluation of BMS-955829, a Potent Positive Allosteric Modulator of mGluR5
}

\author{
Fukang Yang,* Lawrence B. Snyder, Anand Balakrishnan, Jeffrey M. Brown, Digavalli V. Sivarao,
} Amy Easton, Alda Fernandes, Michael Gulianello, Umesh M. Hanumegowda, Hong Huang, Yanling Huang, Kelli M. Jones, Yu-Wen Li, Michele Matchett, Gail Mattson, Regina Miller, Kenneth S. Santone, Arun Senapati, Eric E. Shields, Frank J. Simutis, Ryan Westphal, Valerie J. Whiterock, Joanne J. Bronson, John E. Macor, and Andrew P. Degnan

Bristol-Myers Squibb Research \& Development, 5 Research Parkway, Wallingford, Connecticut 06492, United States

\section{Supporting Information}

ABSTRACT: Positive allosteric modulators (PAMs) of the metabotropic glutamate receptor subtype 5 (mGluR5) are of interest due to their potential therapeutic utility in schizophrenia and other cognitive disorders. Herein we describe the discovery and optimization of a novel oxazolidinone-based chemotype to identify BMS-955829 (4), a compound with high functional PAM potency, excellent mGluR5 binding affinity, low glutamate fold shift, and high selectivity for the mGluR5 subtype. The low fold shift and absence of agonist activity proved critical in the identification of a molecule with an acceptable preclinical safety profile. Despite its low fold shift, 4 retained efficacy in set shifting and novel object recognition models in rodents.

KEYWORDS: mGluR5, positive allosteric modulator, schizophrenia, cognition, neurotoxicity

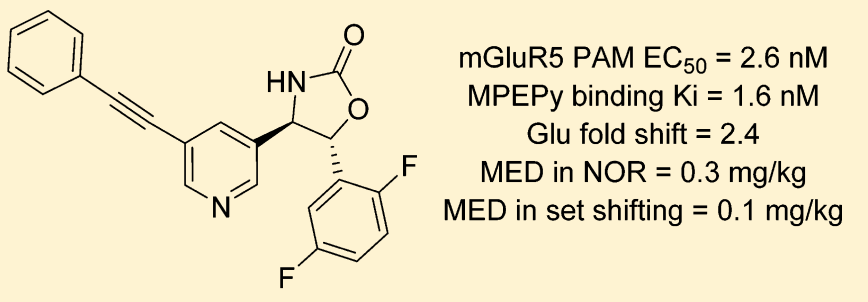

4, BMS-955829
S chizophrenia is a serious brain disorder that distorts the way a person thinks, acts, expresses emotions, perceives reality, and relates to others. ${ }^{1}$ Some of the most common symptoms include delusions, hallucinations, disorganized speech, disorganized or catatonic behavior, and affective flattening. ${ }^{2}$ The onset of symptoms usually occurs in young adults, with a global lifetime prevalence of $0.3-0.7 \% .^{3}$ The incidence of schizophrenia, without regard to severity or classification, has been estimated to be $\sim 1 \%$ of the United States population or roughly 3.2 million people. Of these 3.2 million people, it is estimated that $60 \%$ are using some form of healthcare, which in 2002, cost an estimated $\$ 63$ billion dollars in the U.S. alone. Tragically, schizophrenia patients die 12-15 years earlier than the general population. While antipsychotic drugs are available to treat schizophrenia, most result in difficult-to-manage side effects such as blurred vision, drowsiness, dizziness, and extrapyramidal symptoms. ${ }^{4}$ Furthermore, atypical antipsychotic medications can cause significant weight gain and changes in metabolism, resulting in an increased risk of diabetes and high cholesterol. ${ }^{5}$ As a result, weight, glucose levels, and lipid levels need to be regularly monitored by a healthcare professional, causing an extra burden on the patient and additional healthcare costs.

Schizophrenia has long been attributed to an excess of dopamine in certain pathways of the brain. More recent evidence implicates $N$-methyl-D-aspartate (NMDA) receptor hypofunction in the glutamate system. Glutamate is the major excitatory neurotransmitter in the human brain and plays a key physiological role in a wide variety of processes. ${ }^{6}$ Glutamatergic neurotransmission occurs mainly through activation of cell surface receptors, including ligand-gated ion channels (ionotropic receptors) and metabotropic glutamate $G$ protein coupled receptors (GPCRs). The metabotropic glutamate receptor family (mGluRs) consists of eight family members that are part of the family 3 GPCR superfamily. These receptors are further subdivided into Group I (mGluR 1, 5), Group II (mGluR 2, 3), and Group III (mGluR 4, 6, 7, 8) based upon sequence homology, receptor signaling, and pharmacology. ${ }^{7}$

The mGlu5 receptor is expressed broadly throughout the CNS with predominantly postsynaptic localization. ${ }^{8}$ mGluR5 is a G $\alpha$ q-coupled receptor that activates phospholipase $\mathrm{C}$ and elevates intracellular calcium levels, resulting in activation of downstream signaling molecules. Recent studies in mGluR5 knockout mice using small molecules that negatively modulate mGluR5 function suggested that blocking mGluR5 function may have therapeutic utility in CNS and peripheral disease states including, pain, anxiety, gastroesophageal reflux (GERD), Parkinson's disease levodopa-induced dyskinesia, and fragile $\mathrm{X}$ syndrome. ${ }^{9}$ The potential for therapies based upon the negative modulation of mGluR5 is somewhat limited by side effects such

Received: November 23, 2015

Accepted: January 3, 2016

Published: January 4, 2016 
as deficits in memory, learning, and sensory processing. ${ }^{10}$ Conversely, mGluR5 positive allosteric modulators (PAMs) have been shown to positively impact cognition in a variety of animal models, ${ }^{11}$ to exhibit efficacy in animal models of psychosis, ${ }^{12,13}$ and to enhance EEG power, which is indicative of an increased state of arousal. ${ }^{14}$ Taken together, these in vivo preclinical findings support the use of mGluR5 PAMs for the treatment of schizophrenia.

Our medicinal chemistry effort began prior to the reports of mGluR5 PAM-based seizures and neurotoxicity. ${ }^{15-17}$ At that time, we targeted the identification of a potent positive allosteric modulator with high in vitro efficacy in the hopes that a high fold shift compound would maximize the potential for robust in vivo efficacy. It was in this context that we undertook an mGluR5 PAM screening effort, which resulted in the identification of lead $\mathbf{1}$. Herein we describe the optimization of lead 1 to identify compound 4 (BMS-955829), a potent and selective positive allosteric modulator of mGluR5.

Oxazolidinone 1 (Figure 1) was identified from a high throughput screening campaign and shown to possess an $\mathrm{EC}_{50}$

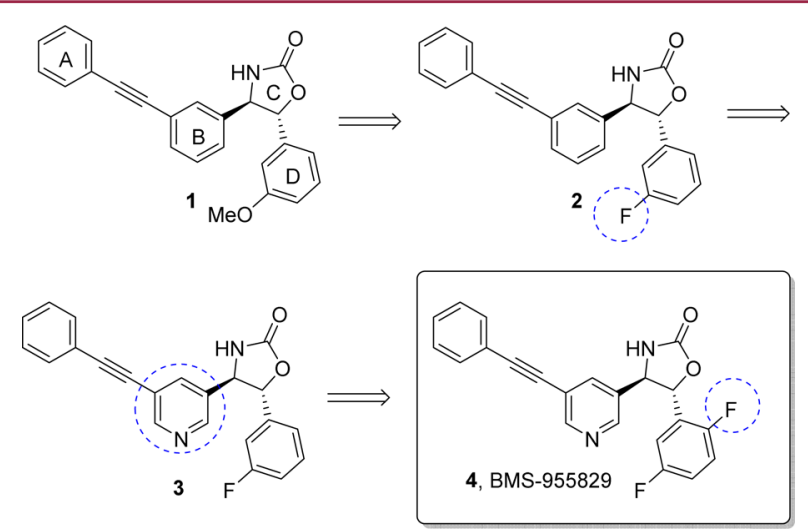

Figure 1. Evolution of 1 to BMS-955829 (4).

of $29 \mathrm{nM}$ for PAM activity in a FLIPR-based mGluR5 functional assay ${ }^{18}$ (Table 1). MPEPy is a small molecule ligand, which binds to the MPEP allosteric site of mGluR5. ${ }^{19}$ In a binding experiment using ${ }^{3} \mathrm{H}-\mathrm{MPEP} y$ as the radiolabeled ligand, $\mathbf{1}$ had binding affinity in good agreement with its functional potency $\left(K_{\mathrm{i}}=13 \mathrm{nM}\right)$. The glutamate fold shift ( $\left.\mathrm{fs}=7.1\right)$ was at a level consistent with that required to achieve in vivo efficacy in the literature. ${ }^{11-14}$ Compound $\mathbf{1}$ was found to be a pure PAM, lacking any inherent mGluR5 agonist activity up to $30 \mu \mathrm{M}$. While $\mathbf{1}$ had good microsomal stability, further evaluation revealed potent time-dependent cytochrome P450 (CYP3A4) inhibition and extensive protein binding. Using $\mathbf{1}$ as our starting point, we set as our goals for the lead optimization efforts: a) to determine the minimum pharmacophore necessary for potent activity; b) increase potency; c) reduce protein binding; and d) minimize time-dependent CYP inhibition. We first examined replacement of the methoxy group with a 3 -fluoro moiety leading to 2 , which retained the excellent glutamate shift response $\left(f_{s}=6.0\right)$ and exhibited a slight increase in potency. Furthermore, 2 was devoid of the time-dependent CYP3A4 inhibition observed with 1 . We next turned our sights toward opportunities to enhance free fraction. To this end, the phenyl "B-ring" of $\mathbf{2}$ (Figure 1) was replaced with the more polar pyridine to afford compound 3 . While increases in free fraction were negligible, compound 3 proved to be 30 times more potent than initial screening hit $\mathbf{1}$ (Table 1). Unfortunately, intraperitoneal (ip) administration of compound 3 to $\mathrm{C} 57 / \mathrm{Bl} 6$ mice at $3 \mathrm{mg} / \mathrm{kg}$ induced convulsions and, in some cases, death ( $1 / 4$ mice). The finding of convulsions (presumably indicative of underlying seizures) in mice was surprising, as there had been no prior reports of mGluR5 PAMs causing convulsions. ${ }^{20}$

During the course of our medicinal chemistry effort, we were fortunate to have identified a number of useful tool compounds with a wide range of pharmacologies. Two such tool compounds are illustrated in Figure 2. PAM 5 was also found

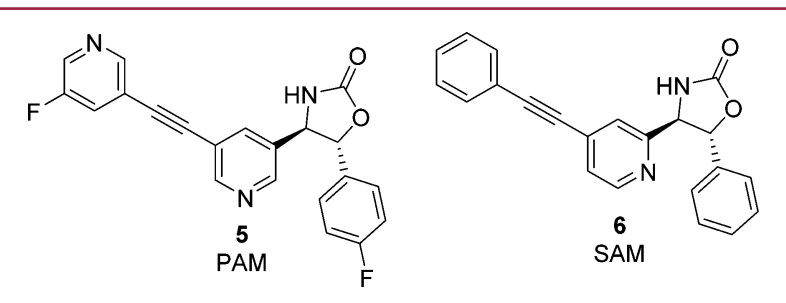

Figure 2. Structurally related tool compounds used in pharmacological blockade experiment.

to cause convulsions in mice (@10 mg/kg ip, $n=4)$ while the structurally-related silent allosteric modulator (SAM) 6 did not (@30 mg/kg ip, $n=4$ ). Coadministration of PAM 5 and SAM 6 demonstrated complete pharmacological blockade of convulsions, strongly suggesting that the convulsions were mechanism-based.

Until this point, we had targeted a compound with a high glutamate fold shift in order to maximize the probability for in vivo efficacy. With the finding of convulsions, however, we reconsidered this approach. Instead, we decided to test the hypothesis that a low fold shift compound might maintain efficacy in rodent models relevant to schizophrenia while mitigating or eliminating the convulsion liability. Earlier structure-activity relationships ${ }^{21}$ indicated that fold shift was

\section{Table 1. Biological Data for Compounds 1-6}

\begin{tabular}{|c|c|c|c|c|c|c|c|}
\hline compd & $\mathrm{PAM} \mathrm{EC}_{50}(\mathrm{nM})^{a}$ & $\operatorname{MPEPy} K_{\mathrm{i}}(\mathrm{nM})^{a}$ & glutamate $\mathrm{EC}_{50}$ shift $^{a}$ & TD HLM-CYP3A4 ${ }^{b}$ & agonist $\mathrm{EC}_{50}(\mu \mathrm{M})^{a}$ & protein binding (\%) & convulsions (dose) \\
\hline 1 & $29 \pm 2$ & $13 \pm 1$ & $7.1 \pm 0.1$ & 9 & $>30$ & 99.7 & no $(10 \mathrm{mg} / \mathrm{kg})$ \\
\hline 2 & $15 \pm 8$ & $6.5 \pm 1.3^{c}$ & $6.0 \pm 0.8$ & 1 & $>30$ & NA & NA \\
\hline 3 & $0.83 \pm 0.08$ & $1.5 \pm 0.1$ & $8.7 \pm 0.7$ & 1 & $>30$ & 99.6 & yes $(3 \mathrm{mg} / \mathrm{kg})$ \\
\hline 4 & $2.6 \pm 1.0$ & $1.6 \pm 0.4$ & $2.4 \pm 0.1$ & 1 & $>30$ & 99.3 & no $(30 \mathrm{mg} / \mathrm{kg})$ \\
\hline 5 & $6.0 \pm 1.5$ & $25 \pm 5$ & $7.1 \pm 0.5$ & 1 & $0.31 \pm 0.05^{d}$ & 96.5 & yes $(10 \mathrm{mg} / \mathrm{kg})$ \\
\hline 6 & $>3000$ & $10 \pm 8$ & NA & 1 & $>3$ & 99.4 & no $(30 \mathrm{mg} / \mathrm{kg})$ \\
\hline
\end{tabular}

${ }^{a}$ Data represents mean \pm SEM ( $\geq 2$ replicates). ${ }^{b}$ Ratio of CYP3A4 inhibition from 30 to 5 min using BFC as the substrate. ${ }^{c 3} \mathrm{H}-\mathrm{MPEP}$ used in place of ${ }^{3} \mathrm{H}$-MPEPy as radioligand. ${ }^{d}$ Agonist activity was confirmed in primary rat cortical astrocytes, which showed comparable expression to HEK transfected cells $\left(B_{\max }\right.$ : HEK-mGLuR5 $10.9 \mathrm{pmol} / \mathrm{mg}$; Astrocytes $6.6 \mathrm{pmol} / \mathrm{mg}$ ). 
exquisitely sensitive to the substitution pattern on the fluorophenyl "D-ring." Further optimization of this aryl ring led us to compound 4 (BMS-955829, Figure 1), which differed from 3 only by addition of a single fluorine atom. Compound 4 was found to be a potent mGluR5 PAM $\left(\mathrm{EC}_{50}=2.6 \pm 1.0 \mathrm{nM}\right.$; $n=6)$, devoid of inherent mGluR5 agonist activity $\left(\mathrm{EC}_{50}>30\right.$ $\mu \mathrm{M})$. The measured binding $K_{\mathrm{i}}$ of 4 was found to be $1.6 \mathrm{nM}$, which was in good agreement with its functional potency. Against a panel of related mGluR receptors (1-4 and 6-8), 4 was shown to be completely selective for mGluR5, lacking any measurable PAM, NAM, or agonist activity at other mGluRs $(>10 \mu \mathrm{M})$. The main differentiator of 4 from other analogues in this series was its remarkably low glutamate fold shift ( $\mathrm{fs}=2.4$ ). Based on the in vitro profile of 4 , we felt that this compound was a good candidate to explore our hypothesis that a decrease in glutamate fold shift would decrease convulsions. Gratifyingly, when compound 4 was administered to mice, no convulsions were observed up to the maximum dose examined $(30 \mathrm{mg} / \mathrm{kg}$, ip). In conjunction with this experiment, ex vivo occupancy experiments showed that the mGlu5 receptors were essentially saturated at both the 10 and $30 \mathrm{mg} / \mathrm{kg}$ doses (94\%), suggesting elimination of the convulsion risk with a low fold shift PAM.

The medicinal chemistry route adopted to prepare 4 (BMS955829) is illustrated in Scheme 1. Diethylphosphonate 8 was

Scheme 1. Synthesis of 4 (BMS-955829) ${ }^{a}$

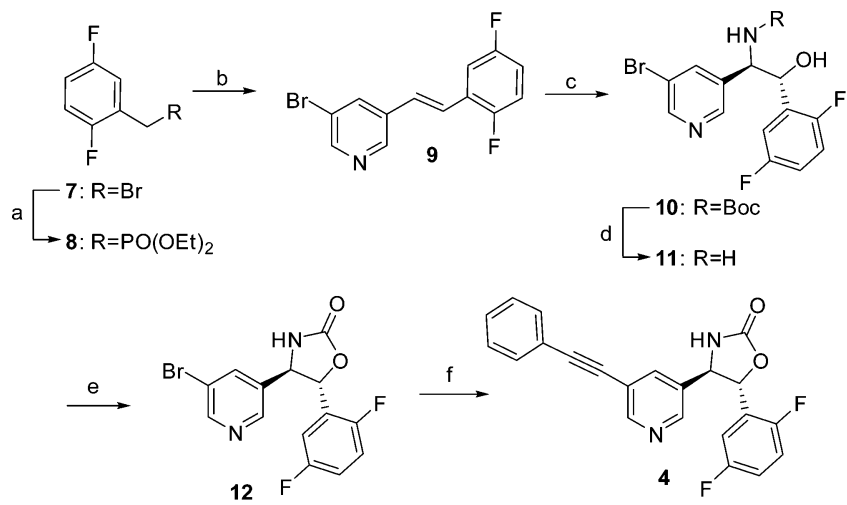

${ }^{a}$ Reagents and conditions: (a) $\mathrm{P}(\mathrm{OEt})_{3}, 160{ }^{\circ} \mathrm{C}, 2-4 \mathrm{~h}, 93-100 \%$; (b) 5-bromonicotinaldehyde, potassium $t$-butoxide, $-10{ }^{\circ} \mathrm{C}$, THF; (c) $\mathrm{K}_{2} \mathrm{OsO}_{4} \cdot 2 \mathrm{H}_{2} \mathrm{O}$, $t$-butylcarbamate, (DHQD) ${ }_{2} \mathrm{PHAL}, t$ - $\mathrm{BuOCl}, \mathrm{NaOH}$ $(0.5 \mathrm{M}), \mathrm{H}_{2} \mathrm{O}$ /propanol, 0 to $22{ }^{\circ} \mathrm{C}, 16 \mathrm{~h}, 32-35 \%$; (d) $\mathrm{HCl} 4 \mathrm{M}$ in dioxane, $50{ }^{\circ} \mathrm{C}, 3 \mathrm{~h}$; (e) CDI, Hünig's base, THF, 23-72\%; (f) ethynylbenzene, $\mathrm{PdCl}_{2}\left(\mathrm{PPh}_{3}\right)_{2}, \mathrm{PPh}_{3}$, CuI, TEA, reflux, $18 \mathrm{~h}, 60-85 \%$.

prepared via a Michaelis-Arbuzov reaction, ${ }^{22}$ employing benzyl bromide 7. Horner-Wadsworth-Emmons olefination ${ }^{23}$ with 5-bromonicotinaldehyde afforded stilbene 9. Asymmetric aminohydroxylation $^{24,25}$ provided $\mathbf{1 0}$ in moderate yield, affording both possible regioisomers (desired/undesired = $4: 1$ ). Separation of the regioisomers by flash chromatography, removal of the Boc group under acidic conditions, and cyclization of the resulting aminoalcohol with carbonyldiimidazole afforded oxazolidinone $\mathbf{1 2}$ in $99 \%$ ee. ${ }^{26}$ Completion of the synthesis via a palladium-mediated Sonogashira cross coupling $^{27}$ with ethynylbenzene provided 4 .

While the lack of convulsions upon administration of $\mathbf{4}$ was encouraging, we needed to determine whether an mGluR5 PAM with a low glutamate fold shift would be efficacious in preclinical behavioral models relevant to schizophrenia. We investigated the efficacy of $\mathbf{4}$ in multiple rodent models designed to mimic the pronounced deficits in cognitive and executive function found in patients with schizophrenia. The novel object recognition (NOR) assay was designed to exploit a rodent's instinctive proclivity to explore novel objects at the expense of familiar ones to assess their capacity for episodic recognition. ${ }^{28}$ Compound 4 was administered subcutaneously (sc) to mice $60 \mathrm{~min}$ prior to training on day 1 . On day 2, one of the familiar objects was replaced with a novel object and time spent with each object was recorded. Figure 3 illustrates results

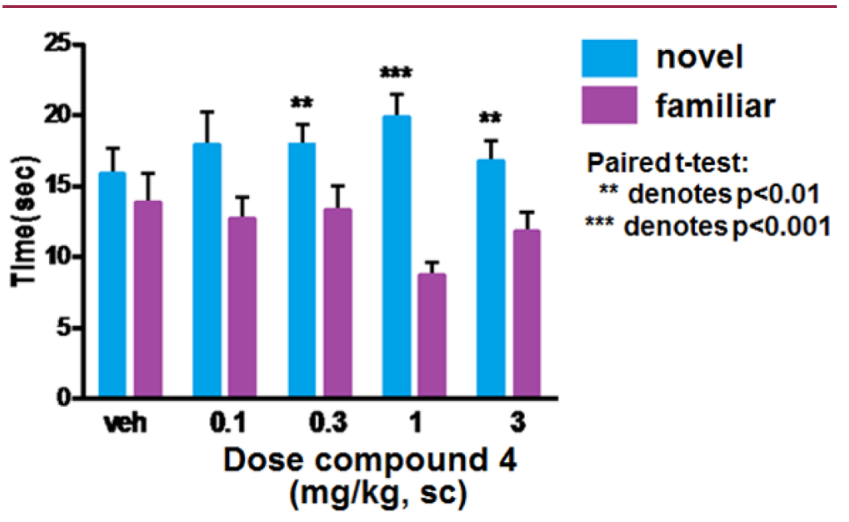

Figure 3. Dose response of 4 in mouse novel object recognition.

obtained with compound 4. Mice dosed with $0.3,1$, or $3 \mathrm{mg} / \mathrm{kg}$ showed significant reductions in time spent with the familiar object, indicating improved recognition memory. Plasma concentrations and ex vivo receptor occupancy data were obtained using satellite animals and indicated total plasma levels of $116 \pm 5 \mathrm{nM}$, total brain levels of $178 \pm 13 \mathrm{nM}$, and $18 \%$ receptor occupancy at the minimum efficacious dose (MED) of $0.3 \mathrm{mg} / \mathrm{kg}$.

In humans, executive function is typically measured using an intradimensional/extra-dimensional (ID/ED) shift task or the Wisconsin card sorting test (WCST). ${ }^{29,30}$ The rat set-shifting experiment was designed to be a rodent analogue of the WCST where the observed ED behavior has been shown to be mediated by the prefrontal cortex (PFC), a region of the brain implicated in mediating working memory for spatial and visual object information. ${ }^{31}$ On day 1 , rats were trained to discriminate on the basis of the first dimension (brightness: light versus dark). Twenty-four hours later, rats were administered MK-801 (an NMDA antagonist used to mimic observed deficits in executive function $)^{32}$ along with varying doses of $\mathbf{4}$ and tested against the second dimension (texture: rough versus smooth), recording the number of trials needed until rats achieved the preselected criterion (eight consecutive correct selections). Figure 4 illustrates results obtained with compound 4. Rats that received $0.1,0.3,1$, or $3 \mathrm{mg} / \mathrm{kg}$ of 4 showed significant reductions in the number of trials required to achieve criterion, indicating reversal of MK-801 induced deficits in executive function. As in the mouse NOR experiment, plasma concentrations and ex vivo occupancy were obtained using satellite animals and indicated total plasma levels of $34 \pm 4 \mathrm{nM}$, total brain levels of $34 \pm 3 \mathrm{nM}$, and $19 \%$ receptor occupancy at the minimum efficacious dose (MED) of $0.1 \mathrm{mg} / \mathrm{kg}$.

Given its robust in vivo efficacy and low potential for convulsions, compound $\mathbf{4}$ was further subjected to a battery of in vitro testing designed to evaluate its potential for drug-drug interactions and toxicity. Against a panel of eight recombinant 


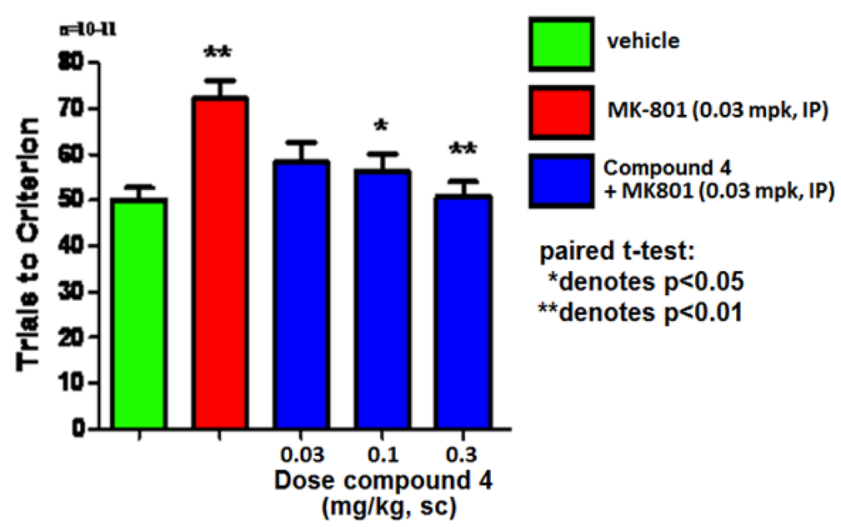

Figure 4. Compound 4 reverses MK-801 deficit in rat set-shifting.

human CYP isoforms, 4 showed low levels of inhibition $\left(\mathrm{IC}_{50} \mathrm{~s}\right.$ $\geq 1.3 \mu \mathrm{M}$ ). Compound 4 had a measured $\mathrm{IC}_{50}$ of $3.6 \mu \mathrm{M}$ in a hERG patch clamp experiment, but given the very low exposure required for efficacy and the high protein binding of 4 , the potential for QT related electrocardiographic findings was deemed to be low. There was minimal inhibition in a sodium patch clamp experiment $(\sim 40 \% @ 10 \mu \mathrm{M})$, indicating little risk of affecting cardiac conduction. Compound $\mathbf{4}$ was tested in a broad panel of receptor and ion channel binding assays, which identified a potential interaction with the progesterone receptor $\left(\mathrm{IC}_{50}=2.3 \mu \mathrm{M}\right)$. Follow-up in a progesterone functional assay demonstrated no significant agonist or antagonist activity at this receptor. Compound 4 was negative in the in vitro micronucleus assay and in an Ames mutagenicity assay, both in the presence and absence of $S 9$ liver fractions, indicating a low potential for genetic toxicity.

The oral bioavailability of compound 4 was examined in multiple species where it ranged from good to excellent (rat $\mathrm{Fpo}=100 \%$, dog $\mathrm{Fpo}=68 \%$, and cyno Fpo $=50 \%) .{ }^{18}$ In rat, 4 showed low clearance at $11 \mathrm{~mL} / \mathrm{kg} / \mathrm{min}$, low volume of distribution $(1.8 \mathrm{~L} / \mathrm{kg})$, and favorable brain uptake $(\mathrm{B} / \mathrm{P} \approx 1)$. A recent disclosure of Parmentier-Batteur et al. reported that repeat dosing of high fold shift PAMs ( $\mathrm{fs}=6-22$ ) resulted in neurotoxicity. ${ }^{16}$ The neurotoxicity was characterized by moderate to severe neuronal necrosis particularly in the auditory complex and hippocampus. On the basis of their studies, the authors speculated that it may be possible to identify a compound with an acceptable margin of safety if fold shift was capped at $\sim 2$. Indeed, $H \& E$ stained sections of the brain, including the auditory complex and hippocampus, showed no evidence of necrosis in rats administered oral doses of 4 at $100 \mathrm{mg} / \mathrm{kg} /$ day for 8 days (day 1: $C_{\max }=41 \mu \mathrm{M}$; $\left.\mathrm{AUC}_{0-24}=751 \mu \mathrm{M} \cdot \mathrm{h}\right) .{ }^{18}$ Upon repeat dosing for 2 weeks in rats and for 5 days in dog, 4 demonstrated an acceptable margin of safety. On the basis of its favorable efficacy and safety profiles, 4 advanced into IND-enabling toxicology studies.

In conclusion, we have described the discovery of BMS955829 (4), a potent and selective positive allosteric modulator of mGluR5 that was devoid of agonist activity $\left(\mathrm{EC}_{50}>30 \mu \mathrm{M}\right)$. Owing to its lack of inherent agonist activity and low fold shift (2.4), 4 presented low potential for convulsions or neurotoxicity, results which were confirmed in mice and rats, respectively. Despite its low fold shift, 4 demonstrated robust in vivo efficacy in preclinical models of schizophrenia, suggesting the potential to reverse cognitive and executive functional deficits in schizophrenia patients. The efficacy and safety profile of 4 suggests the existence of a development path for mGluR5
PAMs possessing a low fold shift $(\sim 2)$. A more detailed disclosure of preclinical efficacy, metabolism, pharmacokinetics, toxicology, and SAR studies leading to the discovery of BMS955829 will be reported in due course.

\section{ASSOCIATED CONTENT}

\section{Supporting Information}

The Supporting Information is available free of charge on the ACS Publications website at DOI: 10.1021/acsmedchemlett.5b00450.

Experimental procedures for the preparation of compound 4, characterization data for 1-6, X-ray crystal structure of 4 , biological experimental methods, a summary of PK parameters for compound 4, and representative slides from the rat neurotoxicity study (PDF)

\section{AUTHOR INFORMATION}

\section{Corresponding Author}

*Tel: 1-203-677-7675. Fax: 1-203-677-7702. E-mail: fukang. yang@bms.com.

\section{Notes}

The authors declare no competing financial interest.

\section{ACKNOWLEDGMENTS}

We thank Dr. Hyunsoo Park and Dr. Qi Gao for X-ray crystal structure determination of compound 4, and Ling Yang for assistance with preparation of the manuscript. We also thank members of Discovery Analytical Sciences for detailed characterizations and members of the Department of Chemical Synthesis for scale-up of $\mathbf{4}$ and its intermediates.

\section{ABBREVIATIONS}

BFC, 7-benzyloxy-4-trifluoromethylcoumarin; CYP, cytochrome P450; CNS, central nervous system; (DHQD) ${ }_{2} \mathrm{PHAL}$, hydroquinidine 1,4-phthalazinediyl diether; EEG, electroencephalography; FLIPR, fluorometric imaging plate reader; fs, fold shift; GERD, gastroesophageal reflux; Glu, glutamate; HLM, human liver microsome; IND, investigational new drug; ip, intraperitoneal; MED, minimum efficacious dose; mGluR5, metabotropic glutamate receptor 5; MK-801, dizocilpine; MPEP, 2-methyl-6-(phenylethynyl)pyridine; MPEPy, 3-methoxy-5-pyridin-2-ylethynylpyridine; NAM, negative allosteric modulator; NMDA, N-methyl-D-aspartate; NOR, novel object recognition; PAM, positive allosteric modulator; SAM, silent allosteric modulator; sc, subcutaneous

\section{REFERENCES}

(1) Schizophrenia: An Overview. http://www.webmd.com/ schizophrenia/what-is-schizophrenia (accessed November 14, 2015).

(2) Diagnostic and Statistical Manual of Mental Disorders, 5th ed. (DSM-5); American Psychiatric Association, 2013.

(3) Van Os, J.; Kapur, S. Schizophrenia. Lancet 2009, 374, 635-645.

(4) Gothelf, D.; Apter, A.; Reidman, J.; Brand-Gothelf, A.; Bloch, Y.; Gal, G.; Kikinzon, L.; Tyano, S.; Weizman, R.; Ratzoni, G. Olanzapine, risperidone and haloperidol in the treatment of adolescent patients with schizophrenia. J. Neural Transm. 2003, 110, 545-560.

(5) Lieberman, J. A.; Stroup, T. S.; McEvoy, J. P.; Swartz, M. S.; Rosenheck, R. A.; Perkins, D. O.; Keefe, R. S.; Davis, S. M.; Davis, C. E.; Lebowitz, B. D.; Severe, J.; Hsiao, J. K. Effectiveness of antipsychotic drugs in patients with chronic schizophrenia. N. Engl. J. Med. 2005, 353, 1209-1223. 
(6) Meldrum, B. S. Glutamate as a Neurotransmitter in the Brain: Review of Physiology and Pathology. J. Nutr. 2000, 130, 1007S$1015 S$.

(7) Conn, P. J.; Pin, J.-P. Pharmacology and functions of metabotropic glutamate receptors. Annu. Rev. Pharmacol. Toxicol. 1997, 37, 205-237.

(8) Shigemoto, R.; Kinoshita, A.; Wada, E.; Nomura, S.; Ohishi, H.; Takada, M.; Flor, P. J.; Neki, A.; Abe, T.; Nakanishi, S.; Mizuno, N. Differential presynaptic localization of metabotropic glutamate receptor subtypes in the rat hippocampus. J. Neurosci. 1997, 17, $7503-7522$.

(9) Emmitte, K. A. mGluR5 negative allosteric modulators: a patent review (2010 - 2012). Expert Opin. Ther. Pat. 2013, 23, 393-408.

(10) Lynch, M. A. Long-Term Potentiation and Memory. Physiol. Rev. 2004, 84, 87-136.

(11) Xu, J.; Zhu, Y.; Kraniotis, S.; He, Q.; Marshall, J. J.; Nomura, T.; Stauffer, S. R.; Lindsley, C. W.; Conn, P. J.; Contractor, A. Potentiating mGluR5 function with a positive allosteric modulator enhances adaptive learning. Learn. Mem. 2013, 20, 438-445.

(12) Gregory, K. J.; Herman, E. J.; Ramsey, A. J.; Hammond, A. S.; Byun, N. E.; Stauffer, S. R.; Manka, J. T.; Jadhav, S.; Bridges, T. M.; Weaver, C. D.; Niswender, C. M.; Steckler, T.; Drinkenburg, W. H.; Ahnaou, A.; Lavreysen, H.; Macdonald, G. J.; Bartolomé, J. M.; Mackie, C.; Hrupka, B. J.; Caron, M. G.; Daigle, T. L.; Lindsley, C. W.; Conn, P. J.; Jones, C. K. N-Aryl Piperazine Metabotropic Glutamate Receptor 5 Positive Allosteric Modulators Possess Efficacy in Preclinical Models of NMDA Hypofunction and Cognitive Enhancement. J. Pharmacol. Exp. Ther. 2013, 347, 438-457.

(13) Xiong, H.; Brugel, T. A.; Balestra, M.; Brown, D. G.; Brush, K. A.; Hightower, C.; Hinkley, L.; Hoesch, V.; Kang, J.; Koether, G. M.; McCauley, J. P., Jr.; McLaren, F. M.; Panko, L. M.; Simpson, T. R.; Smith, R. W.; Woods, J. M.; Brockel, B.; Chhajlani, V.; Gadient, R. A.; Spear, N.; Sygowski, L. A.; Zhang, M.; Arora, J.; Breysse, N.; Wilson, J. M.; Isaac, M.; Slassi, A.; King, M. M. 4-Aryl piperazine and piperidine amides as novel mGluR5 positive allosteric modulators. Bioorg. Med. Chem. Lett. 2010, 20, 7381-7384.

(14) Loomis, S.; McCarthy, A.; Baxter, C.; Kellett, D. O.; Edgar, D. M.; Tricklebank, M.; Gilmour, G. Distinct pro-vigilant profile induced in rats by the mGluR5 potentiator LSN2814617. Psychopharmacol. 2015, 232, 3977-3989.

(15) Rook, J. M.; Noetzel, M. J.; Pouliot, W. A.; Bridges, T. M.; Vinson, P. N.; Cho, H. P.; Zhou, Y.; Gogliotti, R. D.; Manka, J. T.; Gregory, K. J.; Stauffer, S. R.; Dudek, F. E.; Xiang, Z.; Niswender, C. M.; Daniels, J. S.; Jones, C. K.; Lindsley, C. W.; Conn, P. J. Unique signaling profiles of positive allosteric modulators of metabotropic glutamate receptor subtype 5 determine differences in in vivo activity. Biol. Psychiatry 2013, 73, 501-509.

(16) Parmentier-Batteur, S.; Hutson, P. H.; Menzel, K.; Uslaner, J. M.; Mattson, B. A.; O’Brien, J. A.; Magliaro, B. C.; Forest, T.; Stump, C. A.; Tynebor, R. M.; Anthony, N. J.; Tucker, T. J.; Zhang, X.-F.; Gomez, R.; Huszar, S. L.; Lambeng, N.; Fauré, H.; Le Poul, E.; Poli, S.; Rosahl, T. W.; Rocher, J.-P.; Hargreaves, R.; Williams, T. M. Mechanism based neurotoxicity of mGlu5 positive allosteric modulators - Development challenges for a promising novel antipsychotic target. Neuropharmacology 2014, 82, 161-173.

(17) Conde-Ceide, S.; Martínez-Viturro, C. M.; Alcázar, J.; GarciaBarrantes, P. M.; Lavreysen, H.; Mackie, C.; Vinson, P. N.; Rook, J. M.; Bridges, T. M.; Daniels, J. S.; Megens, A.; Langlois, X.; Drinkenburg, W. H.; Ahnaou, A.; Niswender, C. M.; Jones, C. K.; Macdonald, G. J.; Steckler, T.; Conn, P. J.; Stauffer, S. R.; BartoloméNebreda, J. M.; Lindsley, C. W. Discovery of VU0409551/JNJ46778212: An mGlu5 positive allosteric modulator clinical candidate targeting schizophrenia. ACS Med. Chem. Lett. 2015, 6, 716-720.

(18) See Supporting Information for additional detail.

(19) Severance, A. J.; Parsey, R. V.; Kumar, J. S.; Underwood, M. D.; Arango, V.; Majo, V. J.; Prabhakaran, J.; Simpson, N. R.; Van Heertum, R. L.; Mann, J. J. In vitro and in vivo evaluation of $\left[{ }^{11} \mathrm{C}\right] \mathrm{MPEPy}$ as a potential PET ligand for mGlu5 receptors. Nucl. Med. Biol. 2006, 33, $1021-1027$.
(20) Subsequent to the completion of these studies, Rook and coworkers (ref 15) reported that ago-PAMs induce seizures in rats, and Parmentier-Batteur and co-workers (ref 16) reported that high fold shift PAMs devoid of agonist activity lead to neurotoxicity in rats and mice.

(21) Manuscript in preparation.

(22) Michaelis, A.; Kaehne, R. Ueber das verhalten der jodalkyle gegen die sogen. Phosphorigsäureester oder O-phosphine. Ber. Dtsch. Chem. Ges. 1898, 31, 1048-1055.

(23) Horner, L.; Hoffmann, H.; Wippel, H. G. Phosphororganische verbindungen, XII. Phosphinoxyde als olefinierungsreagenzien. Chem. Ber. 1958, 91, 61-63.

(24) Reddy, K. L.; Sharpless, K. B. From Styrenes to enantiopure $\alpha$ arylglycines in two steps. J. Am. Chem. Soc. 1998, 120, 1207-1217.

(25) Sharpless, B. K.; Li, G. Two step synthesis of D- and L- $\alpha$-amino acids and D- and L- $\alpha$-amino aldehydes. U.S. Patent 6,509,506, January 21, 2003.

(26) A 99\% ee by chiral HPLC. Absolute stereochemical assignment was based on X-ray diffraction of compound 4 and refinement of the Flack parameter. Result is consistent with that predicted by ref 25 where trans-stilbene was used as the substrate. ${ }^{18}$

(27) Sonogashira, K. Development of $\mathrm{Pd}-\mathrm{Cu}$ catalyzed crosscoupling of terminal acetylenes with sp2-carbon halides. J. Organomet. Chem. 2002, 653, 46-49.

(28) Mathiasen, J. R; DiCamillo, A. Novel object recognition in the rat: A facile assay for cognitive function. Curr. Protoc. Pharmacol. 2010, $5,1-15$.

(29) Monchi, O.; Petrides, M.; Petre, V.; Worsley, K.; Dagher, A. Wisconsin card sorting revisited: Distinct neural circuits participating in different stages of the task identified by event-related functional magnetic resonance imaging. J. Neurosci. 2001, 21, 7733-7741.

(30) Berg, E. A. A simple objective technique for measuring flexibility in thinking. J. Gen. Psychol. 1948, 39, 15-22.

(31) Smith, A. C.; Stefani, M. R.; Moghaddam, B.; Brown, E. N. Analysis and design of behavioral experiments to characterize population learning. J. Neurophysiol. 2005, 93, 1776-1792.

(32) LaCrosse, A. L.; Burrows, B. T.; Angulo, R. M.; Conrad, P. R.; Himes, S. M.; Mathews, N.; Wegner, S. A.; Taylor, S. B.; Olive, M. F. mGluR5 Positive allosteric modulation and its effects on MK-801 induced set-shifting impairments in a rat operant delayed matching/ non-matching-to-sample task. Psychopharmacology 2015, 232, 251258. 